DOI: https://doi.org/10.47405/mjssh.v6i7.882

\begin{tabular}{|c|c|}
\hline 4.581 & Malaysian Journal of Social Sciences and Humanities (MJSSH) \\
\hline $\begin{array}{l}\text { Malaysian Journal of } \\
\text { Social cciences and }\end{array}$ & Volume 6, Issue 7, July 2021 \\
\hline (MJ-SSH) & e-ISSN : 2504-8562 \\
\hline & $\begin{array}{l}\text { Journal home page: } \\
\text { www.msocialsciences.com }\end{array}$ \\
\hline
\end{tabular}

\title{
Pengaruh Kepimpinan Distributif Terhadap Efikasi Guru: Satu Pemerhatian Awal
}

\author{
Vasuki Muniandy ${ }^{1}$, Zahari Hashim ${ }^{1}$ \\ ${ }^{1}$ Fakulti Pengurusan Ekonomi, Universiti Pendidikan Sultan Idris (UPSI) \\ Correspondence: Vasuki Muniandy (sugiviya@gmail.com)
}

\begin{abstract}
Abstrak
Amalan kepimpinan yang lebih fleksibel dan bercorak perkongsian perlu diamalkan supaya dapat menambah efikasi kendiri guru supaya mereka lebih efektif serta dapat membantu dalam meningkatkan pencapaian sekolah. Justeru itu, penulisan artikel ini bertujuan untuk meninjau pengaruh kepimpinan distributif terhadap efikasi kendiri guru-guru. Tinjauan ini dilakukan berpandukan sumber literatur dan pemerhatian awal mendapati bahawa pemimpin yang mengamalkan kepimpinan distributif mampu mempengaruhi efikasi kendiri guru.
\end{abstract}

Kata kunci: pengaruh, kepimpinan distributif, efikasi kendiri guru

\section{The Influence of Distributive Leadership on Teachers' Self -Efficacy: A Preliminary Observation}

\begin{abstract}
More flexible and partnership leadership practices need to practiced in order to increase the selfefficacy of teachers so that they are more effective and can help in improving school achievement. Therefore, the writing of this article aims to examine the influence of distributive leadership on teachers' self -efficacy. This review was conducted based on literature sources and initial observation found that leaders who practice distributive leadership are able to influence teachers' self-efficacy.
\end{abstract}

Keywords: influence, distributive leadership, self-efficiency, teachers

\section{Pengenalan}

Kejayaan dan keberkesanan pengurusan dan pentadbiran sebuah organisasi dipengaruhi oleh banyak faktor. Faktor paling penting ialah keberkesanan kepimpinan setiap pemimpin dalam sebuah organisasi. Selain berperanan sebagai pengurus dan pentadbir, gaya kepimpinan berkesan pemimpin mampu untuk merangsang komitmen, motivasi dan kepuasan kerja dalam kalangan pekerja (Abdul Ghani, 2017).

Di sekolah misalnya, kejayaan dan keberkesanan pengurusan dan pentadbiran sekolah akan dipengaruhi oleh keberkesanan kepimpinan guru besar. Budaya dan amalan kepimpinan yang berkesan 
dan memuaskan akan sentiasa meningkatkan komitmen, motivasi dan kepuasan kerja dalam kalangan guru (Lokman \& Mohd. Anuar, 2017). Suleyman (2015) menjelaskan bahawa guru besar merupakan pemimpin tertinggi di sekolah berperanan penting untuk memastikan pencapaian dan prestasi sekolah dapat ditambah baik dan ditingkatkan ke tahap yang memuaskan. Guru besar adalah individu yang sangat penting di sesebuah sekolah kerana guru besar atau pengetua inilah yang akan menentukan dasar dan polisi sekolah yang menjadi salah satu faktor kepada kejayaan pelajar dalam pelbagai lapangan termasuklah bidang akademik dan ko-kurikulum. Gaya kepimpinan distributif misalnya mampu mempengaruhi efikasi kendiri dalam kalangan guru.

Lucy (2018) menjelaskan bahawa kepimpinan distributif mampu membantu meningkatkan kemahiran pengajaran guru, meningkatkan motivasi mengajar guru dan sentiasa mendorong guru untuk peka terhadap matlamat untuk meningkatkan pencapaian akademik murid. Sementara itu, Awanis, Ainunmadiah dan Siti (2016) turut menjelaskan bahawa efikasi kendiri dalam kalangan guru dapat ditingkatkan sekiranya kepimpinan distributif mampu menjadi amalan dalam kepimpinan sekolah. Menerusi corak kepimpinan seperti ini, guru akan lebih mudah untuk merancang dan melaksanakan pengajaran dan pembelajaran yang berkesan yang dapat dijadikan perangsang untuk memastikan murid seronok untuk berada di sekolah. Dalam masa yang sama, ia juga mampu meningkatkan kecemerlangan guru dalam melaksanakan amanah dan tanggungjawab mendidik dengan lebih berkesan. Menerusi gaya kepimpinan distributif ini, guru besar membudayakan kepimpinan yang tidak formal dalam pelbagai aspek dan situasi pengurusan dan pentadbiran di sekolah (Lucy, 2018).

Budaya kepimpinan seperti ini memberikan kelebihan kepada semua pihak dalam organisasi untuk berperanan sebagai pemimpin. Walaupun guru besar adalah pemimpin tertinggi di sekolah, namun guru biasa juga boleh berperanan sebagai pemimpin dalam suatu perkara seperti dalam proses membuat keputusan, perancangan tentang penyediaan persekitaran pengajaran dan pembelajaran yang lebih kondusif dan berjaya. Dalam erti kata lain, gaya kepimpinan distributif yang diamalkan oleh guru besar akan memberikan ruang dan peluang kepada guru lain untuk berperanan sebagai pemimpin di sekolah.

\section{Sorotan Literatur}

\section{Pengaruh Kepimpinan Distributif Terhadap Efikasi Guru}

Sistem pendidikan pada masa kini telah berubah akibat oleh pandemik Covid-19. Justeru itu, corak kepimpinan juga harus berubah mengikut peredaran semasa. Pada masa kini kepimpinan dilihat lebih luas dan tidak lagi bersifat tradisional (Tony, 2015). Kepimpinan distributif menjadi semakin terkenal dalam kalangan pengamal polisi, pendidik dan pengkaji dalam bidang pendidikan, kesihatan dan bidang profesional lain (Sally, 2017). Kajian oleh Roznarizah (2015) telah meninjau hubungan kepimpinan distributif dan faktor kontekstual dan efikasi kendiri guru. Pengkaji mendapati guru-guru di Malaysia mempunyai pandangan yang positif terhadap kepimpinan distributif yang menggembleng kepakaran dalam kalangan pemimpin pertengahan dan guru secara individu dan berkumpulan.

Mengikut Shafinaz (2016) menerusi pembahagian tugas pentadbiran dan pengurusan sekolah yang dilakukan secara adil, saksama dan kolektif, maka ia tidak akan mewujudkan perasaan tidak puas hati dengan gaya kepimpinan pengetua. Sebaliknya, guru akan sentiasa memberikan kerjasama terhadap setiap perancangan, arahan dan tindakan yang diberikan oleh guru besar. Secara tidak langsung, guru juga akan lebih mudah untuk melaksanakan amanah dan tugas mereka di sekolah khususnya dalam mendidik murid agar lebih cemerlang dalam kurikulum dan ko-kurikulum (Shakir et al., 2010). Oleh itu, gaya dan corak kepimpinan distributif yang diamalkan oleh guru boleh memberikan impak berkesan kepada murid termasuklah ke atas pencapaian akademik murid.

Menurut Bandura (1986), efikasi kendiri mempengaruhi prestasi dengan meningkatkan usaha dan kecekalan. Mardhiah dan Rabiatul-Adawiah (2016) menyatakan tahap efikasi guru iaitu kebolehan dan kepercayaan guru akan rendah apabila berdepan sesuatu yang sukar dilakukan. Kajian ini membuktikan terdapat hubungan yang signifikan antara kualiti penyeliaan pengajaran dan 
pembelajaran dengan tahap efikasi kendiri guru. Kualiti penyeliaan pengajaran dan pembelajaran membantu dalam meningkatkan tahap efikasi kendiri guru. Kolaborasi antara pemimpin dan guru-guru amat diperlukan. Hal ini kerana apabila guru-guru bekerjasama untuk menambah ilmu dan berkongsi kepakaran, maka ia boleh meningkatkan tahap efikasi kendiri guru. Hulpia et al. (2009) menyatakan bahawa komitmen guru dapat ditingkatkan jika kepimpinan distributif tidak dipraktikkan secara tidak formal.

Selain itu, kajian oleh Aziah, Loh dan Abdul Ghani (2015) menjelaskan bahawa efikasi kendiri dalam kalangan guru dapat ditingkatkan sekiranya kepimpinan distributif mampu menjadi amalan dalam kepimpinan sekolah. Menerusi corak kepimpinan seperti ini, guru akan lebih mudah untuk merancang dan melaksanakan pengajaran dan pembelajaran yang berkesan yang dapat dijadikan perangsang untuk memastikan murid seronok untuk berada di sekolah. Dalam masa yang sama, ia juga mampu meningkatkan kecemerlangan guru dalam melaksanakan amanah dan tanggungjawab mendidik dengan lebih berkesan.

Kajian yang dibuat oleh Abdul Ghani dan Ekerim (2019) menyatakan kepimpinan distributif berpotensi menghasilkan outcome yang positif dan menyumbang kepada hasil organisasi yang lebih produktif. Nazrin (2017) mendapati bahawa amalan kepimpinan distributif menjanjikan peningkatan dalam pengajaran. Kepimpinan distributif dikaitkan dengan perubahan ke arah sekolah yang lebih komprehensif. Persefahaman dan nilai kolektif yang ada dalam kalangan guru akan dapat diperkuatkan dengan menggunakan kepimpinan distributif. Ini kerana cara pembentukan dan setiap tindakan dalam organisasi dapat dijalankan dengan lebih gemilang dan berjaya. Sebagai seorang guru perlu memberi peluang untuk membuat keputusan dan juga mendorong lebih kompetensi dalam kemajuan untuk meningkatkan nilai efikasi pendidikan yang memuaskan (Harris, 2015). Menurut Siva (2014) kepimpinan distributif sebagai gabungan beberapa ciri kepimpinan yang berkesan seperti kerjasama yang efektif dalam satu pasukan kerja, hubungan antara kakitangan dalam organisasi yang bersifat intuitif dan amalan institusi organisasi yang komprehensif dan berjaya. Kajian yang dijalankan oleh Siva dan Yin (2014) pula membuktikan bahawa kepimpinan distributif dapat mengurangkan tekanan kerja sekali gus dapat meningkatkan tahap kecekapan guru-guru untuk menjadi tenaga pengajar yang lebih efisien. Perkara yang sama turut dinyatakan oleh Rosnarizah dan Zulifli (2009) yang menyifatkan kepimpinan distributif sebagai satu bentuk kepimpinan formal, mempunyai perancangan yang strategik dan berkembangan dengan progresif. Amalan kepimpinan seperti ini seharusnya menjadi budaya dalam kalangan kepimpinan di sekolah agar dapat meningkatkan keberkesanan peranan sekolah sebagai institusi pendidikan yang berjaya dan berkesan. 


\section{PENULIS \& TAJUK}

Rosnarizah Abdul Halim.

(2015). Kepimpinan

Distributif, Faktor

Kontekstual dan Efikasi

Kendiri Guru di Malaysia

Shafinaz A.Maulod, Chua

Yan Piaw, Hussein Ahmad,

Leong Mei Wei \& Shahrin

Alias. (2016). Kecerdasan

Emosi Pengetua dan

Hubungannya Dengan

Efikasi Kendiri Guru

Sekolah Menengah

Mardhiah Bt Johari \&

Rabiatul-Adawiah Bt Ahmad

Rashid. (2016). Hubungan

Kualiti Penyeliaan

Pengajaran dengan Efikasi

Kendiri Guru.

\section{TAHUN}

\section{Kajian ini merupakan kajian}

kuantitatif dengan menggunakan pendekatan kajian tinjauan.

2016 Kajian ini menggunakan kaedah kuantitatif secara inferensi-

korelasi dengan menggunakan pendekatan tinjauan (survey) melalui soal selidik untuk mengkaji hubungan antara pengaruh kecerdasan

emosi(pemboleh ubah bebas) terhadap efikasi kendiri guru (pemboleh ubah bersandar).

Kajian ini dilaksanakan untuk mengkaji hubungan antara penyeliaan pengajaran dan pembelajaran dengan tahap efikasi kendiri guru. Kajian ini adalah berbentuk kajian tinjauan. Soal selidik digunakan sebagai kaedah pengumpulan data.

\section{DAPATAN}

Penyelidik merumuskan bahawa guruguru di Malaysia mempunyai pandangan yang positif terhadap kepimpinan distributif yang menggembleng kepakaran dalam kalangan pemimpin pertengahan dan guru secara individu dan berkumpulan.

Penyelidik menunjukkan bahawa kecerdasan emosi pengetua mempengaruhi efikasi kendiri guru dimana kecerdasan emosi pengetua mempunyai empat dimensi iaitu, kesedaran kendiri, pengurusan kendiri, perhubungan dan kesedaran sosial.

Dapatan kajian terhadap hubungan yang signifikan antara kualiti penyeliaan pengajaran dan pembelajaran dengan tahap efikasi kendiri guru. Kekuatan korelasi antara kualiti penyeliaan pengajaran dan pembelajaran dengan tahap efikasi kendiri guru berada pada kekuatan positif.

\section{IMPLIKASI \& CADANGAN}

Kajian ini telah berjaya memecahkan kemelut kekurangan kajian empirikal pengaruh dan kesan kepimpinan distributif terhadap efikasi kendiri guru.

Pemimpin sekolah yang mampu mengawal dan menguasai emosinya dan bersikap positif lebih mudah untuk berinteraksi, kurang agresif, lebih senang membantu orang lain,

mempunyai komen yang membina dan sentiasa menggalakkan guru untuk bekerja. Diharapkan hasil dapatan kajian ini berupaya membantu meningkatkan khazanah ilmu terutamanya dalam bidang kepimpinan pendidikan.

Secara keseluruhannya, jelas menunjukkan bahawa efikasi kendiri guru mempunyai hubungan yang sangat lemah dengan kualiti penyeliaan pengajaran dan pembelajaran. Kualiti penyeliaan pengajaran dan pembelajaran dapat meningkatkan efikasi kendiri guru pada kadar yang rendah. 
PENULIS \& TAJUK

Aziah Ismail, Loh Hooi Yen

\& Abdul Ghani Kanesan

Abdullah. (2015). Komuniti

Pembelajaran Profesioanal

dan Efikasi Kendiri Guru

Sekolah Menengah di Pulau

Pinang.

Mohd Norakmar Omar, Siti

Noor Ismail \& Abd Latif

kasim. (2019). Hubungan

Kepimpinan Teknologi

Pengetua dan Efikasi Kendiri

Guru.

Abdul Ghani Kanesan

Abdullah \& Ekerim A/P Din

Chen. (2019). Pengaruh

Moderator Bagi Komuniti

Pembelajaran Profesioanal

Terhadap Kepimpinan

Instruksional Pengetua dan

Efikasi Kendiri Guru.

Nazrin Bin Halim. (2017),

Pengaruh Kecerdasan Emosi

Dan Efikasi Guru Terhadap

Stail Disiplin Guru Di Kedah

Dan Perlis.

\section{TAHUN METOD}

\section{5}

Kajian ini menggunakan kaedah tinjauan dengan menggunakan soal selidik sebagai instrumen dalam pengumpulan data kajian.

Kajian ini menggunakan kaedah Cross-sectioanl survey melalui borang soal selidik.

Strategi penyelidikan kuantitatif telah digunakan dalam kajian ini. Reka bentuk kajian, kaedah tinjauan dapat mengumpul data terus daripada subjek yang dikaji dan dapat membuat generalisasi terhadap populasi.

2017 Kajian ini dijalankan secara kaedah tinjauan dengan menggunakan borang soal selidik untuk mengumpul maklumat.

\section{DAPATAN}

Dapatan kajian, kewujudan amalan KPP di sekolah tidak mempunyai pengaruh dengan peningkatan tahap efikasi kendiri guru.

IMPLIKASI \& CADANGAN

Kajian ini telah membuktikan secara statistik bahawa tidak wujud pengaruh yang signifikan antara amalan KPP di sekolah dengan tahap efikasi kendiri guru.

Kajian ini telah membuktikan hubungan yang signifikan antara kepimpinan teknologi pengetua dengan efikasi kendiri guru.

Kajian ini adalah detik permulaan kepada kajian lanjutan yang lebih fokus kepada kepimpinan lain selain daripada kepimpinan teknologi.

Dapatan kuantitatif ini telah menunjukkan komuniti pembelajaran profesional bertindak sebagai moderator terhadap hubungan antara amalan kepimpinan Instruksioanal dengan efikasi kendiri guru.

Secara keseluruhannya dapatan kajian ini telah menunjukkan komuniti pembelajaran profesional mempunyai hubungan antara amalan kepimpinan Instruksional dengan efikasi kendiri guru.

Dapatan kajian ini menunjukkan

Dapatan hasil kajian ini bahawa kecerdasan emosi dan efikasi guru mempunyai pengaruh yang paling kuat terhadap stail disiplin perundingan. menyumbangkan input baharu tentang implementasi stail disiplin guru kepada KPM,JPN, IPG, IAB, dan PPD untuk mengenal pasti stail disiplin yang diamalkan oleh guru dalam sistem pendidikan negara. 


\begin{tabular}{|c|c|c|c|c|}
\hline PENULIS \& TAJUK & TAHUN & METOD & DAPATAN & IMPLIKASI \& CADANGAN \\
\hline $\begin{array}{l}\text { Siva Rabindarang \& Yin Yin } \\
\text { Khoo. (2014). Refleksi } \\
\text { Tenaga Pengajar Terhadap } \\
\text { Kepimpinan Distributif dan } \\
\text { Tekanan kerja dalam } \\
\text { Pendidikan Teknik dan } \\
\text { Vokasional Akademika. }\end{array}$ & 2014 & $\begin{array}{l}\text { Kajian ini berbentuk kualitatif } \\
\text { dan teknik pengumpulan data } \\
\text { dilaksanakan dengan kaedah } \\
\text { temu bual dengan menggunakan } \\
\text { soalan separa berstruktur. }\end{array}$ & $\begin{array}{l}\text { Dapatan kajian menunjukkan bahawa } \\
\text { kepimpinan distributif diamalkan } \\
\text { dalam pendidikan teknik dan } \\
\text { vokasional. }\end{array}$ & $\begin{array}{l}\text { Kajian ini menunjukkan bahawa } \\
\text { tenaga pengajar dalam pendidikan } \\
\text { teknik dan vokasional bersetuju } \\
\text { bahawa amalan kepimpinan distributif } \\
\text { dapat mengurangkan tekanan kerja. }\end{array}$ \\
\hline $\begin{array}{l}\text { Zuraidah Jualiana Bt. } \\
\text { Mohamad Yusoff, Siti Noor } \\
\text { Bt. Ismail, Yahya B. Don. } \\
\text { (2015). Pengaruh } \\
\text { Kepimpinan Distributif } \\
\text { Terhadap Persekitaran } \\
\text { Sekolah. }\end{array}$ & 2015 & $\begin{array}{l}\text { Kajian ini berbentuk deskriptif } \\
\text { korelasi yang mengaplikasikan } \\
\text { tinjauan keratan rentas (Cross- } \\
\text { Sectioanal survey) berdasarkan } \\
\text { soal selidik yang dijawab oleh } \\
\text { responden. }\end{array}$ & $\begin{array}{l}\text { Kepimpinan distributif memberi } \\
\text { pengaruh tertinggi dari dimensi } \\
\text { mempamerkan model, memberi } \\
\text { galakan, menginspirasikan } \\
\text { perkongsian visi, misi, dimensi } \\
\text { membenarkan bertindak dan dimensi } \\
\text { mencabar proses. }\end{array}$ & $\begin{array}{l}\text { Kepimpinan distributif terbukti } \\
\text { berperanan penting dalam } \\
\text { mempengaruhi persekitaran sekolah } \\
\text { dan kepentingan ini dapat dilihat } \\
\text { berdasarkan kepada hubungan dan } \\
\text { pengaruh kepimpinan distributif ke } \\
\text { atas kualiti persekitaran sekolah yang } \\
\text { dikaji. }\end{array}$ \\
\hline $\begin{array}{l}\text { Azhar Harun, Ramli Basri, } \\
\text { Zaidol Akmaliah Lope Pihie } \\
\text { \& Soaib Asimiran. (2016). } \\
\text { Hubungan Antara } \\
\text { Kepimpinan Distrubutif } \\
\text { Pengetua dan kepimpinan } \\
\text { Guru di Sekolah Menengah. }\end{array}$ & 2016 & $\begin{array}{l}\text { Kajian yang dijalankan } \\
\text { merupakan kajian yang bersifat } \\
\text { kuantitatif dan menggunakan } \\
\text { kaedah tinjauan. }\end{array}$ & $\begin{array}{l}\text { Hubungan linear signifikan positif } \\
\text { diperoleh daripada dimensi-dimensi } \\
\text { kepimpinan distrubutif dan } \\
\text { kepimpinan guru dengan skor } \\
\text { disrtibutif meningkat maka skor } \\
\text { kepimpinan guru meningkat. }\end{array}$ & $\begin{array}{l}\text { Pengetua mempunyai tahap amalan } \\
\text { yang tinggi terhadap kepimpinan } \\
\text { distrubutif dan guru-guru mempunyai } \\
\text { tahap amalan kepimpinan guru yang } \\
\text { tinggi di sekolah menengah. }\end{array}$ \\
\hline
\end{tabular}




\section{Kesimpulan}

Kesimpulannya, artikel ini telah dapat meneroka beberapa aspek penting dalam pengaruh kepimpinan distributif dan efikasi kendiri guru. Ulasan ini mendapati bahawa terdapat kajian-kajian yang mengkaji pengaruh atau hubungan dengan kepimpinan distributif dan efikasi kendiri guru. Analisis kajian lepas membuktikan bahawa kepimpinan distributif mempunyai hubungan dan interaksi secara kolektif antara pemimpin iaitu guru besar dan juga guru di sekolah. Amalan kepimpinan seperti ini juga mampu membawa perubahan yang sangat besar terhadap pengurusan dan pentadbiran sekolah yang mana mampu meningkatkan kepuasan kerja dalam kalangan guru. Akhir sekali, kejayaan seseorang pemimpin dipengaruhi oleh gaya kepimpinan yang bersesuaian dapat membantu meningkatkan tahap efikasi kendiri guru dan sekali gus memberi kejayaan dalam melaksanakan tugas dengan lebih efektif.

\section{Rujukan}

Abdul Ghani Abdullah, Abd. Rahman Abd. Aziz \& Mohammed Zohir Ahmad (2017).Gaya-Gaya Kepimpinan Dalam Pendidikan. Kuala Lumpur: Pts Professional Publishing Sdn. Bhd.

Awanis Binti Mohd, Ainunmadiah Binti Mohd Nawawi, Siti Noor Binti Ismail. (2016). Tahap Efikasi Guru Dan Hubungannya Dengan Pencapaian Sekolah Di Sekolah-Sekolah Menengah Dalam Daerah Bachok, International Seminar on Generating Knowledge Through Research, UUMUMSIDA, 25-27 October 2016, Universiti Utara Malaysia, Malaysia

Aziah Ismail, Loh, H. Y. \& Abdul Ghani Kanesan Abdullah (2015). Komuniti Pembelajaran profesional dan efikasi kendiri guru sekolah menengah di Pulau Pinang. Jurnal Kepimpinan Pendidikan, 2(2).

Aziz, Tahir., Ahmad, Z. M., \& Ghazali, D. (2018). Amalan Kepimpinan transformasional guru besar dengan hubungannya terhadap kepuasan kerja guru sekolah daerah Miri. Seminar Antarabangsa Isu-Isu Pendidikan (ISPEN 2018)

Bandura, A. (1986). Human agency in social cognitive theory. American Psychologist, 44(9), 11751184.

Bush Tony. (2015). Teacher leadership: Construct and practice. Educational Management Administration \& Leadership, 43(5), 671-672.

Cohen, Manion, L., \& Morrison, K. (2011). Research Methods in Education (7th ed.). Routledge. https://doi.org/10.4324/9780203720967

Dipaola MF, Hoy WK. School Characteristics that Foster Organizational Citizenship Behavior. Journal of School Leadership, 15(4), 387-406.

Harris, A. (2015). Distributed Leadership Different Perspective. Springer Science And Business Media B.V.

Hulpia, H., Devos, G., \& Rosseel, Y. (2009). The relationship between the perception of distributed leadership in secondary schools and teacher's and teacher leaders' job satisfaction and organisational commitment. American Educational Research Association. http://www.jstor.org/stable/40284858

Lokman Mohd. Tahir \& Mohd. Anuar Abd. Rahman.(2017). Orientasi Kepimpinan Pengetua Sekolah. Johor Bahru: Penerbit Utm Press.

Lucy Sibanda, (2018). Distributed Leadership In Three Diverse Public Schools: Perceptions Of Deputy Principals In Johannesburg, Issues In Educational Research, 28(3), 781-796

Rosnarizah, A. H. \& Zulkifli, A. M. (2009). Prevalens kepimpinan distributif di sekolah-sekolah menengah terpilih di Malaysia. Kertas kerja yang dibentang di Seminar Nasional Pengurusan dan Kepimpinan Pendidikan Ke-16, Institut Aminuddin Baki, Genting Highlands. Malaysia: Kementerian Pendidikan Malaysia.

Sally, W. Y., Wan, E.H.F.L., \& Keith, K. C., (2017). Teachers' perception of distributed leadership in Hong Kong primary schools. School Leadership \& Management.

Shakir, F. J., Isa, J. H., \& Mustafa, P. O. (2011). Perception Towards Distributed Leadership In School Improvement. International Journal Of Business And Management, 6(10).

Shafinaf A Maulod, Chua, Y. P., Hussein, A, Leong, M. W., \& Shahrin, A. (2016). Kecerdasan emosi pengetua dan hubungannya dengan efikasi kendiri guru sekolah menengah. Jurnal Kepimpinan Pendidikan, 3(3), 54-75. 
Malaysian Journal of Social Sciences and Humanities (MJSSH), Volume 6, Issue 7, (page 408 - 415), 2021

DOI: https://doi.org/10.47405/mjssh.v6i7.882

Siva A/L/Rabindarang, (2014). Kepimpinan Distributif, Komitmen Organisasi dan Tekanan Kerja di Kolej Vokasional, Malaysia. Universiti Pendidikan Sultan Idris.

Suleyman Goksoy, (2015). Distributed Leadership In Educational Institutions, Journal Of Education And Training Studies, 3(4), 110-118 